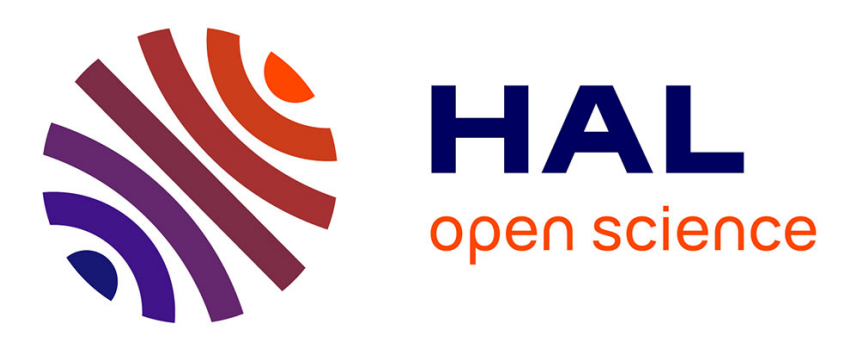

\title{
Modeling point velocity and depth statistical distributions in steep tropical and alpine stream reaches
}

Virginie Grandgirard, Nicolas Lamouroux, R. Mons

\section{To cite this version:}

Virginie Grandgirard, Nicolas Lamouroux, R. Mons. Modeling point velocity and depth statistical distributions in steep tropical and alpine stream reaches. Water Resources Research, 2014, 50 (1), p. 427 - p. 439. 10.1002/2013WR013894 . hal-01070488

\section{HAL Id: hal-01070488 \\ https://hal.science/hal-01070488}

Submitted on 1 Oct 2014

HAL is a multi-disciplinary open access archive for the deposit and dissemination of scientific research documents, whether they are published or not. The documents may come from teaching and research institutions in France or abroad, or from public or private research centers.
L'archive ouverte pluridisciplinaire HAL, est destinée au dépôt et à la diffusion de documents scientifiques de niveau recherche, publiés ou non, émanant des établissements d'enseignement et de recherche français ou étrangers, des laboratoires publics ou privés. 


\title{
Modeling point velocity and depth statistical distributions in steep tropical and alpine stream reaches
}

\author{
V. Girard, ${ }^{1,2}$ N. Lamouroux, ${ }^{1}$ and R. Mons ${ }^{1}$ \\ Received 29 March 2013; revised 2 December 2013; accepted 19 December 2013; published 17 January 2014.
}

[1] Statistical hydraulic models predict the frequency distributions of point hydraulic variables, relative to their reach-averaged values, in a stream reach based on its average characteristics (e.g., discharge, depth, width, average particle size). The models initially developed in Europe have not been tested for steeper streams $(>4 \%)$ with coarse grain size. We recorded water velocities and depths in 44 reaches of steep streams in tropical islands and the Alps during 69 surveys. We fitted the observed distributions of velocities and depths using a mixture of two distributions, one with low variance and the other with a high variance. Then, we predicted the mixing parameter on the basis of the reach-averaged characteristics. We compared the observed and predicted frequencies for five classes of velocities, including a class of negative velocities, and four classes of water depths. The predictions of class frequencies have a bias of $\leq 5 \%$. Our statistical model of velocity distribution predicts the frequencies of velocity classes with an explained variance between 33 and $72 \%$ for four classes of velocity and null for a class of intermediate velocity. The statistical model of depth distributions was less efficient with an explained variance between 25 and $38 \%$ for three classes of depth and null for large depths. The average Froude number, the total height of large drops relative to the reach length and the average slope are the main explanatory variables of velocity and depth distributions.

Citation: Girard, V., N. Lamouroux, and R. Mons (2014), Modeling point velocity and depth statistical distributions in steep tropical and alpine stream reaches, Water Resour. Res., 50, 427-439, doi:10.1002/2013WR013894.

\section{Introduction}

[2] The variability of point hydraulic parameters (e.g., velocity, depth, shear stress) in a stream reach influences chemical, biological, and physical processes [e.g., Nikora, 2009; Smith et al., 2011]. Modeling the variability of hydraulic parameters is therefore essential for predicting the characteristics of flows [Chiu and Tung, 2002] and their ecological consequences [Poff and Allan, 1995]. Different methods are available for describing and predicting the frequency distributions of point hydraulic variables at the reach scale and how they vary as a function of discharge. Deterministic numerical models are the tools most frequently used to predict and map local hydraulic patterns within reaches. They solve the equations of conservation of mass and momentum and are calibrated using topographic and hydraulic field surveys. Although constantly improved, numerical models are still difficult to use for describing point hydraulic variables under complex flow conditions (e.g., torrential flows, high relative roughness) [Ricken-

\footnotetext{
${ }^{1}$ IRSTEA Lyon, UR MALY, Villeurbanne, France.

${ }^{2}$ ASCONIT Consultants, Espace Scientifique Tony Garnier, Lyon, France.

Corresponding author: V. Girard, ASCONIT Consultants, Espace Scientifique Tony Garnier, 6-8 Espace Henry Vallée, FR-69366 Lyon CEDEX, France. (virginie.girard@asconit.com)
}

C2013. American Geophysical Union. All Rights Reserved. 0043-1397/14/10.1002/2013WR013894 mann and Recking, 2011] where much of the energy is lost in falls and hydraulic jumps [Wilcox et al., 2011]. They are also sensitive to the quality of topographic and hydraulic input data [Legleiter et al., 2011]. The sophistication of these models, from one-dimensional to two-dimensional or three-dimensional models, has increased their potential for describing complex small-scale patterns but has also increased their complexity and the field investment required [Cooper and Tait, 2010].

[3] Statistical hydraulic models have been proposed as complements to deterministic approaches, for example in situations where numerical models can accurately describe average reach hydraulics (e.g., stage-discharge relationships) but are less efficient for capturing small-scale hydraulic variations. Statistical modeling is based on the observation of frequency distributions of point hydraulic variables such as velocity, water depth, and bed shear stress [Lamouroux et al., 1992, 1995; Lamouroux, 1998; Stewardson and McMahon, 2002]. Frequency distributions of hydraulic variables within cross sections or within reaches have comparable shapes in many natural streams and vary with increasing discharge rate in a predictable manner. For example, velocity and depth distributions tend to have normal shapes at high discharges [Stewardson and McMahon, 2002]. Therefore, these frequency distributions can be modeled by parametric probability functions [Dingman, 1989; Lamouroux et al., 1995].

[4] Several papers (Table 1) have demonstrated that the parameters describing the frequency distribution of hydraulic variables in reaches across a wide range of streams in 


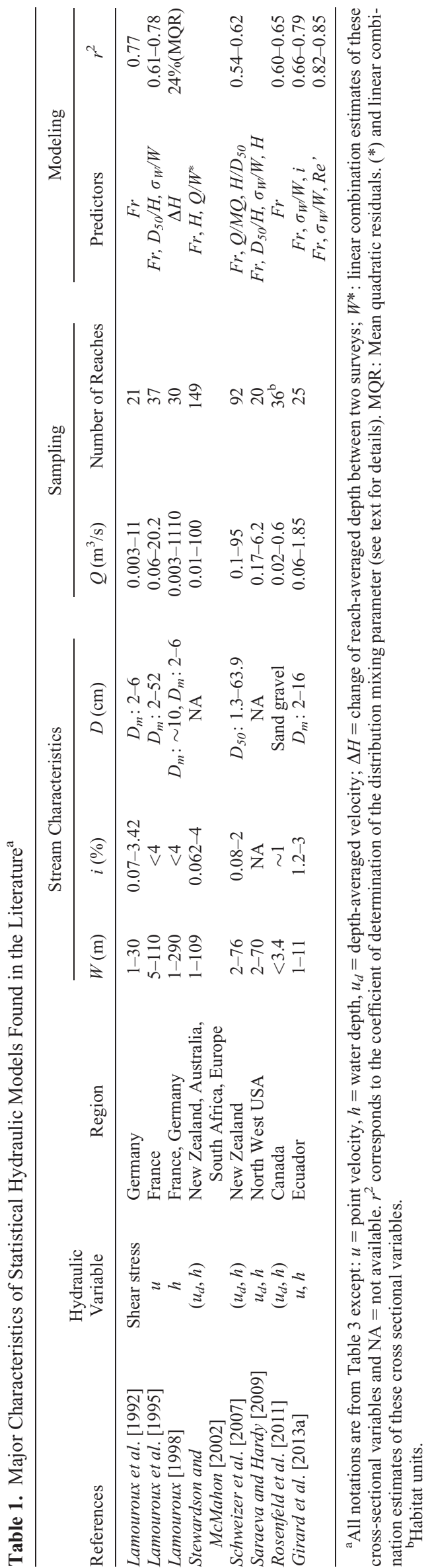

the world can often be predicted on the basis of reachaveraged characteristics (e.g., discharge, mean depth, mean width, mean particle size) [Lamouroux et al., 1995; Lamouroux, 1998; Schweizer et al., 2007; Saraeva and Hardy, 2009; Rosenfeld et al., 2011]. Consequently, knowledge of mean depth-discharge and width-discharge relationships in reaches (i.e., at-a-reach hydraulic geometry relationships) [Stewardson, 2005; Lamouroux, 2007] can be used to predict the distributions of point hydraulic variables at various discharge rates using statistical hydraulic models. Compared to deterministic models, statistical hydraulic models are not spatially explicit and most of them have been developed for reaches with limited morphologic alterations. However, statistical models enable simple predictions of point hydraulic variables and their changes with discharge, because at-a-reach hydraulic geometry relationships can be estimated easily from measurements made at a few discharge rates in the reach [Stewardson, 2005]. Applying the models does not require the complete topography of the reach or detailed velocity measurements. Therefore, statistical models are attractive for cost-effective large-scale hydraulic descriptions [Petts, 2009; Conallin et al., 2010].

[5] The generality of statistical hydraulic models has been tested in different hydro-geomorphological contexts. For example, Rosenfeld et al. [2011] showed that the bivariate velocity and depth distribution models of Schweizer et al. [2007] calibrated in streams in New Zealand provided a sufficiently good approximation for streams in Canada. Likewise, the univariate models of Lamouroux et al. [1995] and Lamouroux [1998], developed in Europe, have been tested in the streams of the Nooksack basin in the State of Washington [Saraeva and Hardy, 2009] and in the Andean streams in Ecuador [Girard et al., 2013a], demonstrating relatively good fit to the observed distributions. Nonetheless, the latter two works showed that regional improvement of the models is possible. More generally, the comparison of all statistical models is complicated by the fact that bivariate models consider the statistical distribution of depth-averaged velocities while others consider the distributions of at-a-point velocities (i.e., time-averaged but not depth-averaged along a vertical profile; Table 1). Overall, the transferability of statistical hydraulic models across different river types requires better understanding.

[6] Statistical hydraulic models have been developed in streams with a slope $<4 \%$ and with a substrate particle size generally $<64 \mathrm{~cm}$ (Table 1). Their development is needed for steep streams with coarse grain size, where the application of deterministic approaches is particularly difficult. Resistance to flow takes specific forms in steep streams [Wohl and Meritt, 2008] and likely affects the distribution of point hydraulic variables. According to the flow resistance partitioning concept, resistance to flow can be split into three main components: grain, form, and spill resistance [e.g., Einstein and Barbarossa, 1952; David et al., 2011]. Grain resistance is linked to viscous forces and the drag around the particles. Form resistance is due to the irregularities of the bed, while spill resistance is linked to the accelerations and decelerations of the flow in the presence of steps [e.g., Wilcox et al., 2011]. In streams with moderate slope and grain size, grain resistance often dominates and can be simply represented by the average 
diameter of the particles relative to water depth. However, in streams with steep slope and large grain size, the large particles act as forms, and the resistance of forms and spills dominate [Lee and Ferguson, 2002; Wohl and Meritt, 2008; Zimmermann, 2010; David et al., 2011]. Although relative grain size has already been taken into account in some statistical hydraulic models [e.g., Lamouroux et al., 1995; Schweizer et al., 2007] (Table 1), the descriptors of other types of resistance are candidate variables for predicting hydraulic parameters in streams with coarse grain size.

[7] In this study, we developed statistical models of at-apoint velocity and water depth distributions in streams with steep slopes and coarse grain size, using measurements of velocities and water depths performed during 69 surveys (reach $\times$ date combinations) in 44 stream reaches in tropical islands and the French Alps. As in Lamouroux et al. [1995] and Lamouroux [1998], only univariate distributions were considered and we modeled the velocity distributions and water depths distributions as a combination of two extreme distributions, one with low variance and the other with high variance. We then predicted the mixing parameter of these distributions as a function of the reachaveraged characteristics, including descriptors of form and spill resistance.

\section{Methods}

\subsection{Study Area}

[8] The streams sampled were located in the French Alps and in four tropical islands: Guadeloupe and Martinique (in the French Caribbean), and Reunion and Mayotte (in the west Indian Ocean). Due to the climatic, geological and pedological conditions in these regions, the streams generally present steep slopes and large substratum particle sizes. The rainfall regimes of the islands are characterized by substantial temporal variations due to cyclonic and tropical disturbances. Annual rainfall varies between 1.5 and $12 \mathrm{~m} / \mathrm{yr}$ on average [Chaperon et al., 1983; Robert, 2001]. However, the hydrology of alpine streams is determined by lower rainfalls (between 1.2 and $1.5 \mathrm{~m} / \mathrm{yr}$ on average, data from Météo-France, 2012, http://pluiesextremes.meteo.fr/) and snowmelt from April to September. Nonetheless, severe storms in spring and summer can cause considerable peak discharges.

\subsection{Reach Characteristics}

[9] We sampled 44 reaches from 1 to 4 times each $(20$ reaches sampled at 2 discharges, 1 reach at 3 discharges, and 1 reach at 4 discharges), i.e., a total of 69 surveys (Table 2). The reach length (following the main flow direction) varied from 14 to 69 times the wetted width of the water surface to include the available diversity of geomor-

Table 2. Sampling Characteristics for the Six Data Sets Considered

\begin{tabular}{lcc}
\hline Data Set & Number of Reaches & Number of Surveys \\
\hline Alps & 5 & 13 \\
Guadeloupe & 15 & 25 \\
Martinique & 7 & 11 \\
Mayotte & 4 & 4 \\
Reunion & 13 & 16 \\
\hline
\end{tabular}

phic sequences encountered in the streams (i.e., step-pool, step-step, and cascades) [Montgomery and Buffington, 1997] (Figure 1 and Table 3). The reaches were mainly located at the head of the catchments at an average altitude of $500 \mathrm{~m}$ and an average distance of $5.1 \mathrm{~km}$ from the watershed boundary. The surface area of the catchments upstream of the reach varied from 0.1 to $42 \mathrm{~km}^{2}$ and the average slope of the catchments varied from 14 to $78 \%$. The mean interannual discharges (i.e., daily discharge averaged over years with available data) ranged from 0.047 to $2.770 \mathrm{~m}^{3} / \mathrm{s}$ (these estimations exclude the Reunion island due to lack of data). The reach water slopes $(i)$ varied from 1 to $24 \%$ and was $10 \%$ on average, i.e., a few tropical reaches with moderate slopes were included to increase the range of stream types studied. Bed substrates were typically composed of large boulders and bedrock, with many boulders protruding above the water. Reaches had limited morphologic alterations and instream wood was occasionally present (1-4 occurrences in $23 \%$ of the surveys); they had low sinuosity, low width depth-ratios (23 on average) and were generally composed of a single channel, though small islands were sometimes observed.

\subsection{Sampling Methods}

[10] In each survey, we measured the discharge rate $(Q)$ according to the velocity-area method. The hydraulic variables were sampled on a grid composed of cross-sections regularly spaced along the reach and verticals regularly spaced along the cross-sections. The choice of a regular spacing of our verticals was made to reduce subjectivity as much as possible, and was particularly adapted to our steep streams were point velocities and point depths can vary strongly along short distances. The fixed spacing between cross-sections and the fixed spacing between the verticals along the cross sections were defined so that at least 15 cross-sections and an average of seven verticals along these cross sections were sampled. Once these fixed spacing had been defined, the verticals were sampled along a crosssection until the opposite bank was reached. At the last vertical along a cross-section, the additional width that would have been needed to position an additional vertical was used as the first spacing on the next cross-section. This procedure helped to avoid choosing specific verticals along the sections. Finally, we sampled an average of 148 verticals per survey [minimum 77, maximum 265] situated along 21 cross-sections [15-33] (Table 3).

[11] For each cross section, we measured the wetted width $(w)$. At each sampling vertical along the crosssection, we measured the total water depth $(h)$, one to three point velocities $(u)$ along the vertical, and the point bed particle size $(d)$. $u$ was measured perpendicular to the cross-section with an electromagnetic flow meter (Marsh McBirney FLO MATE 2000; http://www.hachflow.com/) at various depths $(0.2 h, 0.4 h$, and $0.8 h$ above the bed). When $h$ was $<20 \mathrm{~cm}, u$ was measured at $0.4 h$ only. Point velocities $u$ were measured over a $10 \mathrm{~s}$ period, extended to $20 \mathrm{~s}$ when the flow was judged turbulent or very slow. The flow meter could measure velocities between -0.15 and 6 $\mathrm{m} / \mathrm{s}$, with an accuracy of about $0.015 \mathrm{~m} / \mathrm{s} \pm 2 \%$ of the measured velocity. Negative velocities typically occurred downstream of boulders, in plunge pools and in eddies. $d$ was estimated as the size of the bed particle situated 

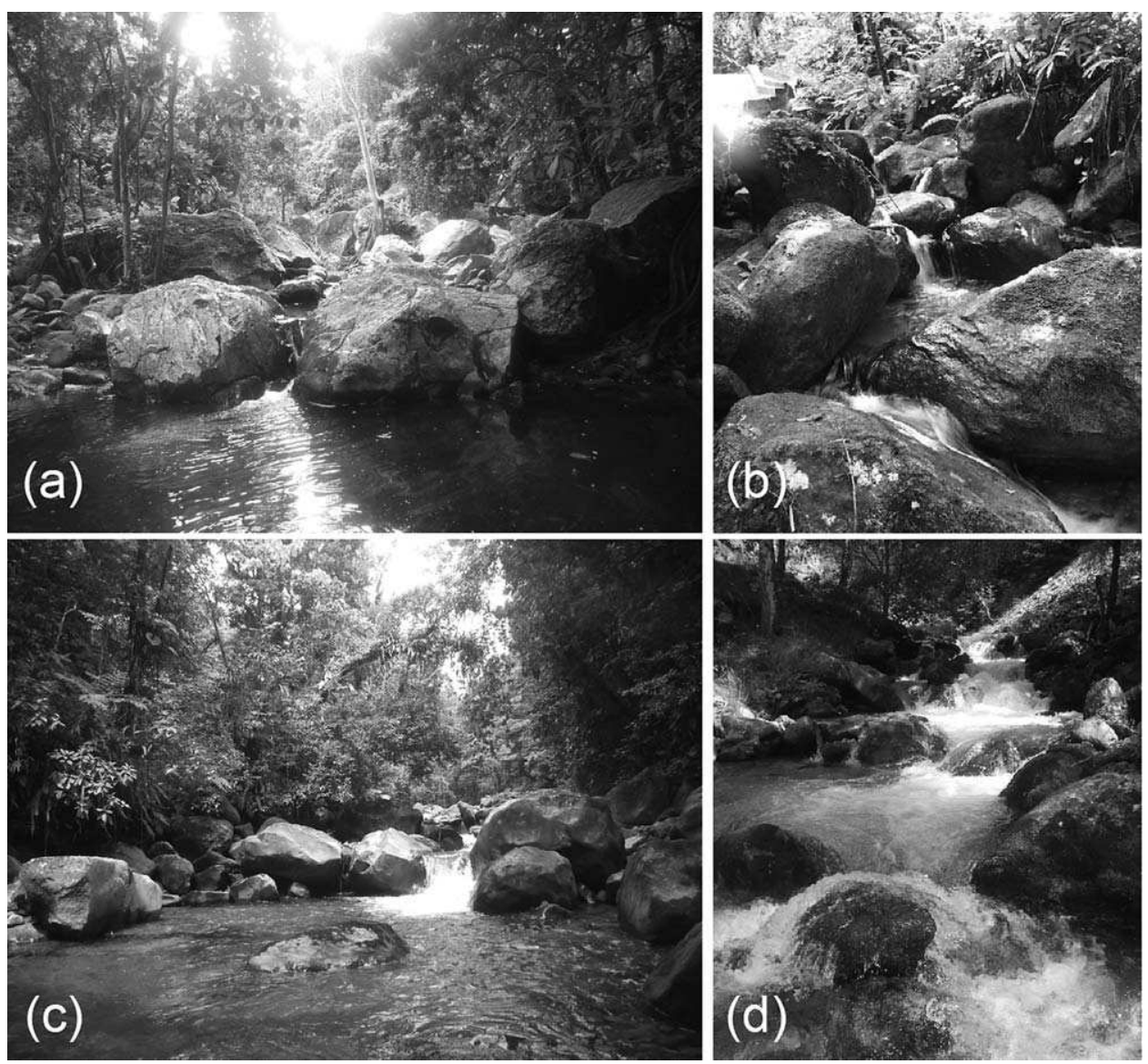

Figure 1. Examples of sampled reaches $(a-c)$ in the tropical islands and $(d)$ in the Alps.

exactly at the sampling vertical. The size was estimated as an ordinal value for $d<25 \mathrm{~cm}$ according to the Wentworth classification modified by Malavoi and Souchon [2002], but for larger boulders it was estimated as $2 \sqrt{A \times B / \pi}$ here $A$ is the lateral axis perpendicular to the flow and $B$ is the vertical axis of the particle considered. Verticals located along the wetted width but out of the water (e.g., on an emergent block or island) were subjected to particle size measurement only.

[12] Between each cross section, in order to describe the types of resistance typical of steep streams, we measured

Table 3. Notations and Characteristics of Reaches and Surveys

\begin{tabular}{|c|c|c|c|c|c|}
\hline & Notation & Minimum & Mean & Median & Maximum \\
\hline Length (m) & $L$ & 60 & 159 & 120 & 600 \\
\hline Upstream average catchment slope (\%) & $I_{b}$ & 13.8 & 36.1 & 31.6 & 77.6 \\
\hline Catchment area $\left(\mathrm{km}^{2}\right)$ & $S_{b}$ & 0.12 & 10.37 & 7.30 & 42.00 \\
\hline Distance from source $(\mathrm{km})$ & $d_{\text {upstream }}$ & 0.4 & 5.1 & 4 & 17.3 \\
\hline Mean interannual discharge ${ }^{a}\left(\mathrm{~m}^{3} / \mathrm{s}\right)$ & $M Q$ & 0.047 & 0.653 & 0.421 & 2.770 \\
\hline Survey discharge $\left(\mathrm{m}^{3} / \mathrm{s}\right)$ & $Q$ & 0.003 & 0.345 & 0.217 & 1.228 \\
\hline Reach water slope $(\%)$ & $i$ & 1 & 10 & 9.2 & 24 \\
\hline Number of verticals per reach & $N_{\text {vert }}$ & 77 & 148 & 144 & 265 \\
\hline Number of point velocities measured per reach & $N_{\text {vtot }}$ & 115 & 224 & 220 & 353 \\
\hline Mean wetted width at survey discharge (m) & $W$ & 1.24 & 5.89 & 4.88 & 19.55 \\
\hline Coefficient of variation of wetted width & $\sigma_{W} / W$ & 0.19 & 0.35 & 0.34 & 0.77 \\
\hline Reach-averaged velocity at survey discharge (m) & $U$ & 0.017 & 0.206 & 0.150 & 0.611 \\
\hline Reach-averaged depth at survey discharge $(\mathrm{m})$ & $H$ & 0.08 & 0.26 & 0.24 & 0.63 \\
\hline Reach-averaged particle size submerged (m) & $D_{m}$ & 0.001 & 0.146 & 0.192 & 0.399 \\
\hline 84th quantile of particle size distribution (submerged and emerged) (m) & $D_{84}$ & 0.276 & 0.957 & 0.757 & 2.560 \\
\hline Reach Reynolds number $\left(\times 10^{-6}\right)$ & $R e^{\prime}$ & 0.003 & 0.049 & 0.038 & 0.165 \\
\hline Relative roughness & $D_{84} / H$ & 0.78 & 4.17 & 3.13 & 31.70 \\
\hline Sediment sorting & $\delta_{D}$ & 0.31 & 0.71 & 0.61 & 2.47 \\
\hline Cumulative step height over the reach, divided by reach length (\%) & $i_{\text {step }}$ & 0.07 & 5.34 & 4.70 & 19.69 \\
\hline
\end{tabular}

${ }^{\mathrm{a}}$ Data missing for Reunion. 
the height of each large drop (i.e., torrential passages of over $20 \mathrm{~cm}$ in height) along the reach thalweg. At every four cross sections, we measured the slope of the two banks with a clinometer. The width corresponding to the bank considered was chosen as equal to the wetted width to ensure repeatability. Last, between every four cross sections, we measured the water slope.

\subsection{Data Processing}

[13] For each survey, we calculated the distribution of the relative velocity $f_{u}(u / U)$, where $U$ is the reach-averaged velocity. Note that in our statistical approach, $u$ are at-apoint values that are not averaged along verticals. Consistently, we defined $U$ as the average of point velocities weighted by the volume of water they represent. To do this, we first interpolated point velocities along each vertical (estimation of $u$ every $\mathrm{cm}$ ) between all available velocity measurements (i.e., one or three values). Before the interpolation, we assigned a value of 0 to the velocity at the bottom and the velocity measured at the highest depth for the velocity at the surface.

[14] Piecewise linear interpolation was used (i.e., linear interpolation between consecutive velocity measurements along the vertical) as previously done by Lamouroux et al. [1995] and Girard et al. [2013a]. Vertical velocity profiles measured in steep streams are often not logarithmic and have variable shapes [Marchand et al., 1984; Wiberg and Smith, 1991; Wohl and Thompson, 2000]. However, many of them vary more close to the bed than further above. In these conditions, we considered that the linear piecewise interpolation from measurements made at $0.2 h, 0.4 h$, and
$0.8 h$ was a consistent hypothesis. Tests of alternative interpolation methods (e.g., splines) visually confirmed that the interpolation method had a weak effect on the observed velocity distributions (see an example in Figure 2). Because all interpolated point velocities across the reach represented a similar volume of water (due to their regular spacing in all three dimensions), we calculated the average reach velocity $U$ as the average of all the interpolated point velocities. In parallel, we calculated the distribution of the relative depth $f_{h}(h / H)$, where $H$ is the reach-averaged depth.

[15] As was done for the European models, for illustrative purposes and to facilitate the numerical convergence of model fits, all the velocity and depth distributions were discretized and expressed as frequency distributions of 20 regular classes of relative velocity and relative depth ranging from $u / U=h / H=0$ to $u / U=h / H=5$. One additional class of velocity was defined to account for all measured negative values. The frequencies of high velocities and depth values falling outside this range were assigned to the highest class.

\subsection{Fitting Models to the Observed Velocity and Depth Distributions}

[16] Following the approach of Lamouroux et al. [1995] and Lamouroux [1998], we expressed $f_{u}$ and $f_{h}$ as a mixture of two extreme distributions, one with high variance and one with low variance. The mixing parameter, $s_{\text {mix }}$ for velocity and $t_{m i x}$ for depth, quantifies the contribution of the two extreme distributions and varies between 0 and 1 (equations (1) and (2), Figure 2).
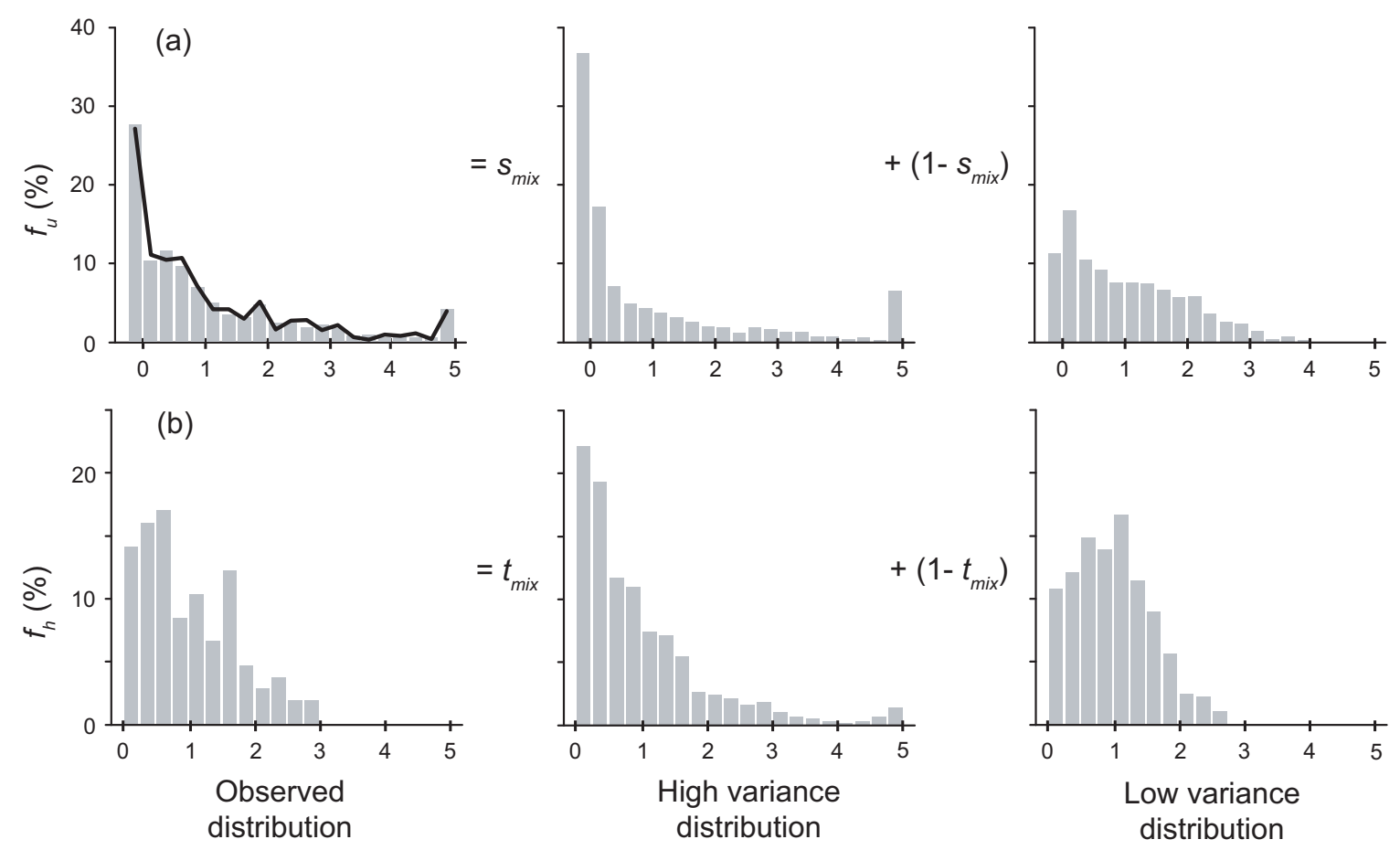

Figure 2. Principle of the modeling of observed (a) velocity and (b) depth distribution as a mixture of two empirical distributions. Observed distributions (bars) are from one of our tropical reaches. The line added on the observed velocity distribution (a) is an example of velocity distribution obtained with an alternative interpolation of point velocities along verticals (spline instead of piecewise linear interpolation). 


$$
\begin{aligned}
& f_{u}(u / U)=s_{\text {mix }} \cdot f_{u}^{1}(u / U)+\left(1-s_{\text {mix }}\right) \cdot f_{u}^{2}(u / U) \\
& f_{h}(h / H)=t_{\text {mix }} \cdot f_{h}^{1}(h / H)+\left(1-t_{\text {mix }}\right) \cdot f_{h}^{2}(h / H)
\end{aligned}
$$

[17] The extreme distributions were obtained empirically from the average of four observed extreme distributions. In equations (1) and (2), $f_{u}^{1}$ and $f_{h}^{1}$ are the means of the four distributions with the largest variance of $u / U$ or $h / H$. $f_{u}^{2}$ and $f_{h}^{2}$ are the mean of the four frequency distributions with the smallest variance. However, the surveys in which $U<0.05$ $\mathrm{m} / \mathrm{s}$ were excluded from the selection due to the uncertainties on measurements of very low velocities. The choice of averaging four distributions was a compromise for obtaining smoothed distributions that fitted well to the observed extreme distributions. Empirical models were chosen rather than parametric extreme models, as done in previous studies [e.g., Lamouroux et al., 1995], because they appeared more efficient for mimicking our observed distributions and notably the observed frequency of negative velocities. Afterwards, for each of the surveys, $s_{\text {mix }}$ and $t_{\text {mix }}$ were estimated according to the maximum likelihood with the $n \operatorname{lminb}()$ function of the free software $\mathrm{R}[R$ Development Core Team, 2010] and denoted $s_{f i t}$ and $t_{f i t}$.

\subsection{Prediction of the Mixing Parameter as a Function of the Reach-Averaged Characteristics}

[18] The second step consisted in using regressions to explain the mixing parameters $\left(s_{f i t}\right.$ and $\left.t_{f i t}\right)$ from a number of candidate reach-scale explanatory variables; regressions provided the predicted mixing parameter $\left(s_{\text {pred }}\right.$ and $\left.t_{\text {pred }}\right)$. The candidate explanatory variables included the dimensionless variables used in previous statistical hydraulic models (Table 1): the average water slope $i$, a term of relative roughness $D_{84} / H$, the reach Froude number $\mathrm{Fr}=(\mathrm{U} / \sqrt{\mathrm{g} \cdot \mathrm{H}})$ where $g$ is the gravitational acceleration, the reach Reynolds number $\operatorname{Re}=(U \cdot H) / v$ where $v$ is the kinematic viscosity of the water, considered throughout as equal to $10^{-6} \mathrm{~m}^{2} / \mathrm{s}\left(R e^{\prime}=\operatorname{Re} \times 10^{-6}\right.$ is used throughout the paper), and the coefficient of variation of width $\sigma_{W} / W$ among cross-sections. $\mathrm{Fr}$ and $\mathrm{Re}$ ' were lntransformed in regressions to approach normal distributions. Due to the specificity of our steep reaches, our candidate variables also included parameters describing reach heterogeneity and the different forms of resistance: a sediment sorting statistic $\left(\delta_{D}=\log \left(D_{84} / D_{50}\right)\right)$ [David et al., 2010] and the total height of large drops relative to the reach length $\left(i_{\text {step }}\right)$. The latter parameter indicates how much energy is lost in large drops and should reflect spill resistance. $D_{84}$ and $D_{50}$ are calculated on the basis of immerged and emerged particles to integrate the variability of the bed at low and high discharges.

[19] We used logistic regressions to fit $s_{f i t}$ and $t_{f i t}$ as a function of explanatory variables. Selections of explanatory variables in our models were carried out according to a backward stepwise procedure using the Bayesian Information Criterion (BIC) available with the $\mathrm{R}$ software $[R$ Development Core Team, 2010].

\subsection{Comparison of Models}

[20] To evaluate our models, we compared:

1. the observed distributions of $f_{u}$ and $f_{h}$;

2. the fitted distributions of $f_{u}$ and $f_{h}$, which correspond to the best fit of equations (1) and (2) that provide $s_{f i t}$ and $t_{f i t}$;
3 . the predicted distributions of $f_{u}$ and $f_{h}$, which correspond to equations (1) and (2) with the values of the mixing parameters predicted by the reach-averaged characteristics $s_{\text {pred }}$ and $t_{\text {pred }}$. Using linear regressions, we quantified how fits and predictions explained the observed frequencies of five velocity classes and four depth classes: negative velocities $(u / U<0)$, low velocities and depths $(0 \leq u / U$ $<0.5, \quad 0 \leq h / H<0.5)$, intermediate velocities and depths $(0.5 \leq u / U<2,0.5 \leq h / H<2)$, high velocities and depths $(2 \leq u / U<4.75,2 \leq h / H<4.75)$, and very high velocities and depths $(u / U \geq 4.75$, $h / H \geq 4.75)$.

[21] Last, we compared our models to comparable models developed in Europe. To this end, we compared the frequencies observed to predicted frequencies using the model of Lamouroux et al. [1995] whose predictive variables are Fr and $D_{m} / H$ (equation (3) in Lamouroux et al. [1995, p. 5], where $D_{m}$ is the mean particle size). The classes of negative and low velocities, then the classes of high and very high velocities are grouped for this comparison as they were not described in the model of Lamouroux et al. [1995].

\section{Results}

\subsection{Sampling Characteristics}

[22] A total of 15,434 point velocity measurements and 8526 point water depth measurements were performed. The correlation between $h$ and $u$ (interpolated values) remained low in our reaches (i.e., average correlation across reaches: -0.09 ; standard deviation: 0.16 ). The sampling discharges $(Q)$ ranged from 0.003 to $1.228 \mathrm{~m}^{3} / \mathrm{s}$ (i.e., from 4 to $252 \%$ of the mean interannual discharge) and their variation within reach is a factor from 1.1 to 16.7 (median: 1.7) in the reaches sampled at several discharges (Table 3). The characteristic diameter of the particles for which $84 \%$ of particles had a smaller diameter $\left(D_{84}\right)$ varied between 0.276 and $2.560 \mathrm{~m}$. The relative roughness is from 0.78 to 31.70 , and corresponds to large relative roughness conditions $\left(D_{84} / H>0.56\right)$ [Bathurst, 2002] and shallow flow $\left(D_{84} / H>0.25\right)$ [Ferguson, 2007]. The reach $F r$ varied

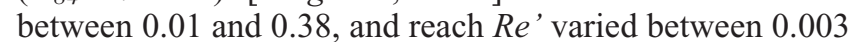
and 0.165 . The coefficient of variation of the wetted width varied between 0.19 and 0.77 and the sediment sorting of 24,11 , and 9 reaches was good $\left(\delta_{D}<0.61\right)$, moderate and poor $\left(\delta_{D}>0.86\right)$, respectively (according to the modified classification of Folk and Ward, in Blott and Pye [2001]). The very high value 2.47 is due to the strong presence of slabs or flagstone.

[23] We occasionally observed inverse within-reach variations between $H$ and $Q$ for five of our 44 reaches and between $W$ and $Q$ for four reaches, in cases where the discharges sampled were close (ratio between the two discharges $\leq 2$ ). Nonetheless, a negative relation between $H$ and $Q$ was observed for a reach in Guadeloupe in spite of a ratio of 2.6 between the two discharges, as the bed had been heavily modified between our surveys.

\subsection{Fitting the Distribution Models to the Distributions Observed}

[24] The models fitted quite well with the observed distributions (Figures 3 and 4, Appendix A). Distributions $f_{u}$ and $f_{h}$ generally evolved from a form with considerable 
(a) Martinique - Madame

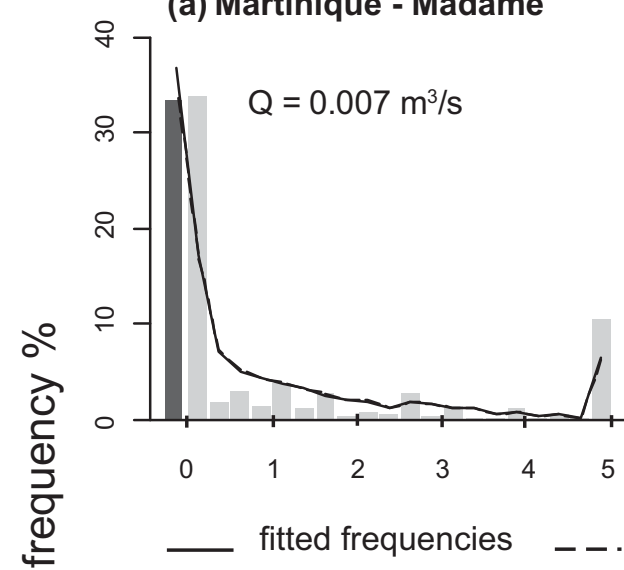

(c) Alps - Vallon

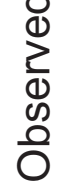

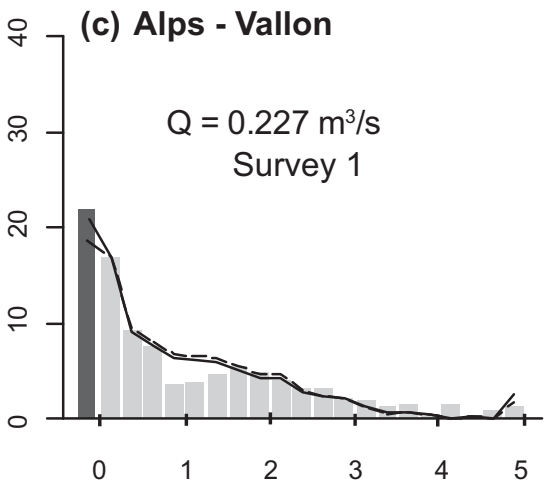

(b) Alps - Béranger

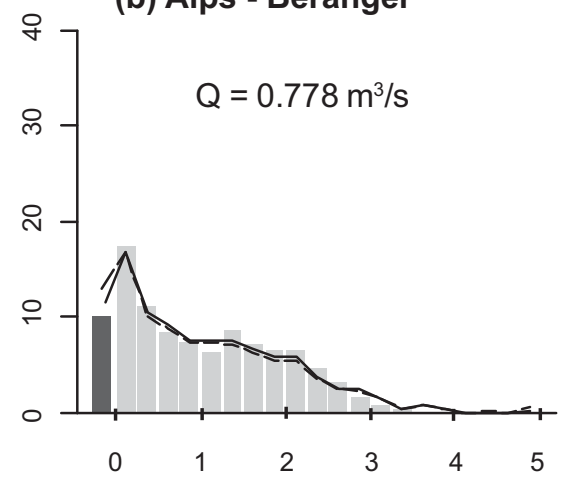

predicted frequencies

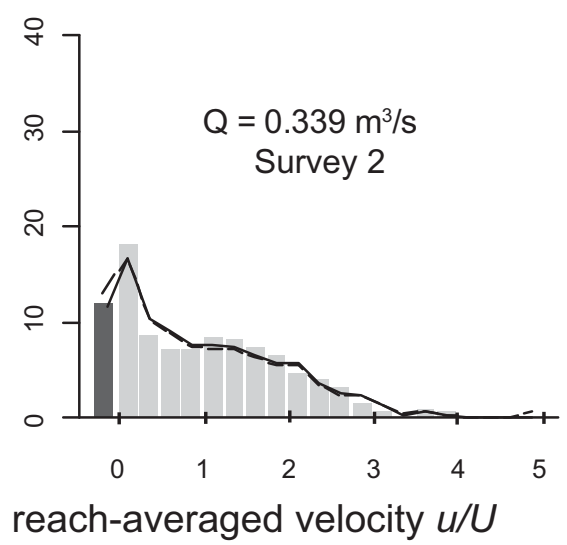

Figure 3. Examples of observed (bars), fitted (line, equation (1)) and predicted (dashed line, equation (3)) velocity distributions in (a) a reach with a high-variance distribution, (b) a reach with a low-variance distribution, and (c and d) a reach sampled at two discharge rates. The black bar corresponds to the frequency of negative velocities.

variance to one with low variance for an increase in discharge between and within reaches (Figures 3 and 4).

[25] The frequencies of intermediate velocity classes varied from 12 to $47 \%$ (Figure 5a) and indicated more heterogeneous distributions than in Ecuador (from $\sim 50$ to $80 \%$ ) [Girard et al., 2013a]. The frequency of high and very high velocities varied little between reaches. The fit between the frequency of low velocity classes and our model was poor, as the latter estimated a comparable frequency in all the streams (Figure 5a). The average bias associated with the fitted frequencies (the mean residual $\varepsilon$ ) is $\leq 5 \%$ in absolute value (Table 4 ). The observed variances explained $(E V)$ by the fits varied between 20 and $83 \%$, except for the low velocity class $(E V=0$ for $0 \leq u<0.5 U$, Figures $5 \mathrm{a}$ and $5 \mathrm{~b}$, Table 4).

[26] The frequencies of deep and very deep water depths varied little between reaches (Figure 6a). The bias between fitted and observed frequencies was $\leq 5 \%$ (Table 4 ). The $E V$ associated with fits varied between 40 and $76 \%$, except for the class of very deep depths $(E V=0$ for $h \geq 4.75 H$, Figures $6 a$ and $6 b$, Table 4).

\subsection{Predictions of Mixing Parameters}

[27] The best model for $s_{\text {pred }}$ includes as explanatory variable $\mathrm{Fr}$ and $i_{\text {step }}$ (equation (3), Figure 7a). A simplified model for $s_{\text {pred }}$ is also proposed as there is no simple way of predicting the evolution of $i_{\text {step }}$ with a change of flow (equation (4)). The best model $t_{\text {pred }}$ includes $F r$ and $i$ (equation (5), Figure $7 \mathrm{~b}$ ). The variables are listed in equations by order of explanatory power and the McFadden $R^{2}$ of the logistic regression [McFadden, 1974] is provided.

$$
\begin{aligned}
& \ln \left[\frac{s_{\text {pred }}}{\left(1-s_{\text {pred }}\right)}\right]=-4.530[ \pm 0.588]-1.580[ \pm 0.186] \\
& \quad \cdot \ln (\text { Fr })+0.159[ \pm 0.036] \cdot i_{\text {step }} \quad R^{2}=0.74 \\
& \ln \left[\frac{s_{\text {pred }}}{\left(1-s_{\text {pred }}\right)}\right]=-3.163[ \pm 0.431]-1.344[ \pm 0.180] \\
& \quad \cdot \ln (\text { Fr }) \quad R^{2}=0.63 \\
& \ln \left[\frac{t_{\text {pred }}}{\left(1-t_{\text {pred }}\right)}\right]=-2.775[ \pm 0.617]-0.838[ \pm 0.185] \\
& \quad \cdot \ln (\text { Fr })+0.087[ \pm 0.030] \cdot i \quad R^{2}=0.34
\end{aligned}
$$

[28] The mixing parameters $s_{\text {pred }}$ and $t_{\text {pred }}$ from surveys in tropical islands span comparable ranges (Figure 7a). On the contrary, the $s_{\text {pred }}$ values of the Alps are relatively low (Figure $7 \mathrm{a}$ ) and present the poorest correlation with $s_{f i t}$ $\left(r^{2}=0.48\right)$. The variance of the hydraulic distributions observed in the Alps is therefore low. For the islands 
(a) Martinique - Picart

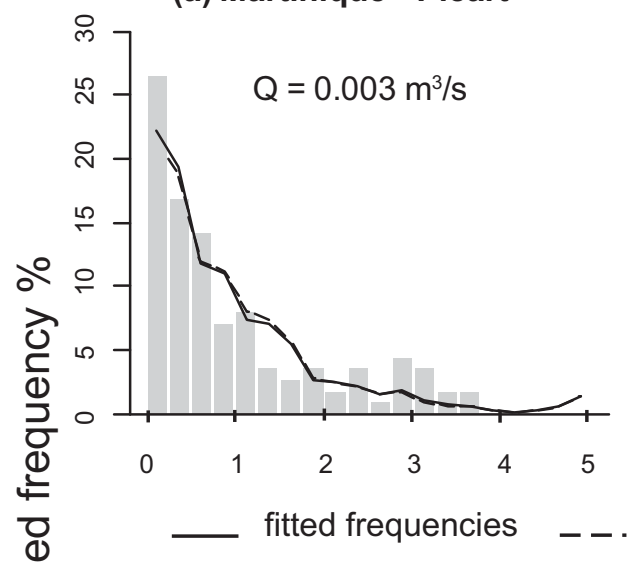

(b) Alps - Béranger

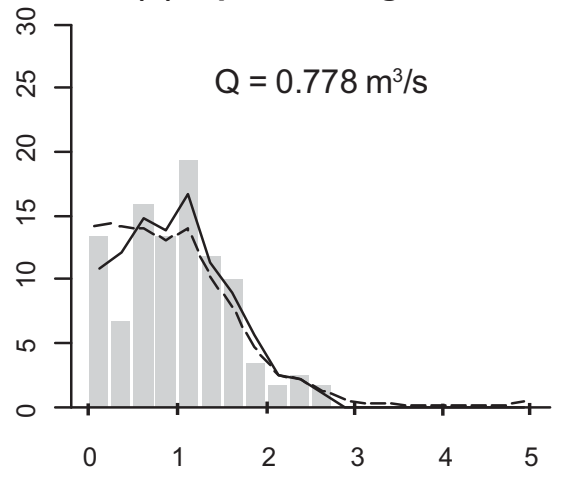

predicted frequencies

(c) Reunion - Roche à Jacquot
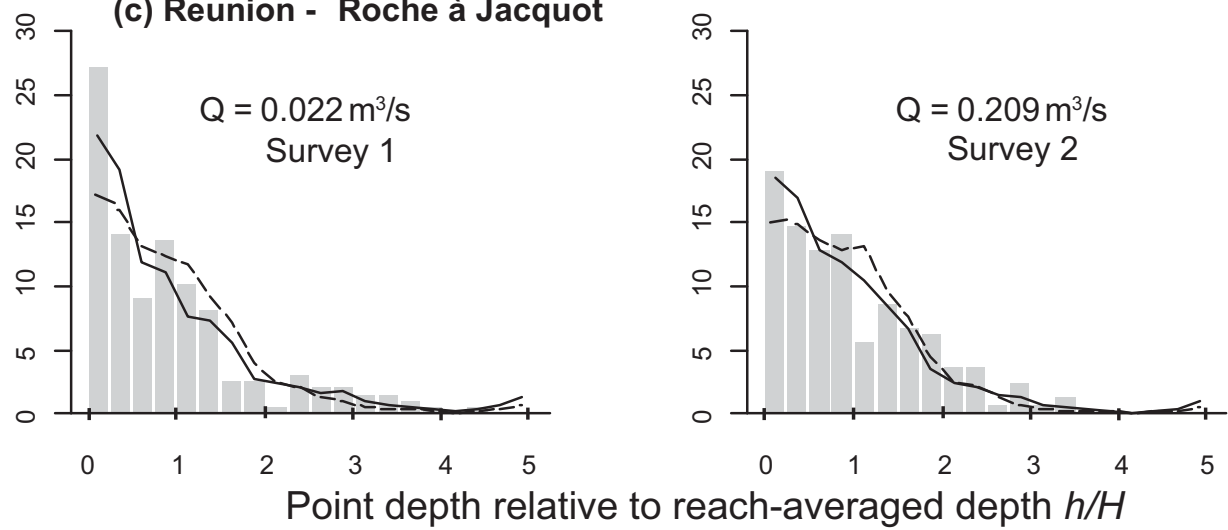

Figure 4. Examples of observed (bars), fitted (line, equation (2)) and predicted (dashed line, equation (5)) depth distributions in (a) a reach with a high-variance distribution, (b) a reach with a low-variance distribution, and (c and d) a reach sampled at two discharge rates.

considered individually, the correlation $r^{2}$ between $s_{\text {pred }}$ and $s_{f i t}$ varies between 0.58 and 0.82 . Furthermore, $s_{f i t}$ and $t_{\text {fit }}$ generally decrease as discharge increases (cf. examples in Figure 7a). The inverse relationship was observed for five of our 44 reaches (regarding velocity) and eight reaches (regarding water depth).

\subsection{Comparison of Predicted and Observed Frequencies}

[29] For both hydraulic variables and their classes, the average bias associated with the predicted frequencies remained $\leq 5 \%$ in absolute value (Table 4 ). For the velocities, the $E V$ associated with predicted frequencies ranged from 33 to $72 \%$ and was null for the class of low velocities $(0 \leq u<0.5 U$, Figure $5 \mathrm{~b}$, Table 4$)$. The $E V$ of our predictions are better ( $E V$ from 60 to $74 \%$ ) than those of the model of European streams [Lamouroux et al., 1995] (EV from 0 to $21 \%$ ) for the low and intermediate velocity classes. For the two models, however, the $E V$ associated with the high velocity classes are null (Figures $5 \mathrm{c}$ and $5 \mathrm{~d}$, Table 4). For depth, the $E V$ associated with predicted frequencies range between 25 and $38 \%$ and are null for the very high depth class $(h>4.75 H$, Figure $6 b)$.

\section{Discussion}

[30] We showed that a common statistical model can predict the form of velocity and depth distributions in sev- eral tropical islands and in the Alps, highlighting the similar statistical hydraulic properties shared by steep streams with coarse grain size. The velocity distribution model can also predict the frequency of negative velocities, which was $>40 \%$ in some of our reaches. Nonetheless, our models do not succeed for every class of velocity and depth, e.g., the frequencies of relative velocities between 0 and 0.5 and the relative depths $>4.75$ are poorly predicted. However, when classes of negative and low velocities are merged, their frequency is well predicted (Figure 5c). This suggests that the weak prediction of the low velocity class could be due to the wrong assignment of close-to-zero velocities to either the negative or low velocity class, due to measurement uncertainties (see methods). Therefore, in practice, predictions of negative and low velocity frequencies could be merged or not, depending on the application objectives. For example, a distinct prediction of the frequency of negative velocities could be useful for estimating the frequency of fine sediment and nutrient trapping; a merged prediction could be useful when modeling hydraulic habitats.

[31] More generally, improvements could be made by increasing the number of parameters in our models. However, this might decrease our ability to predict parameters from average reach characteristics. Considering joint distributions of depth and velocity is also an interesting perspective that would enable linkage of statistical hydraulic 

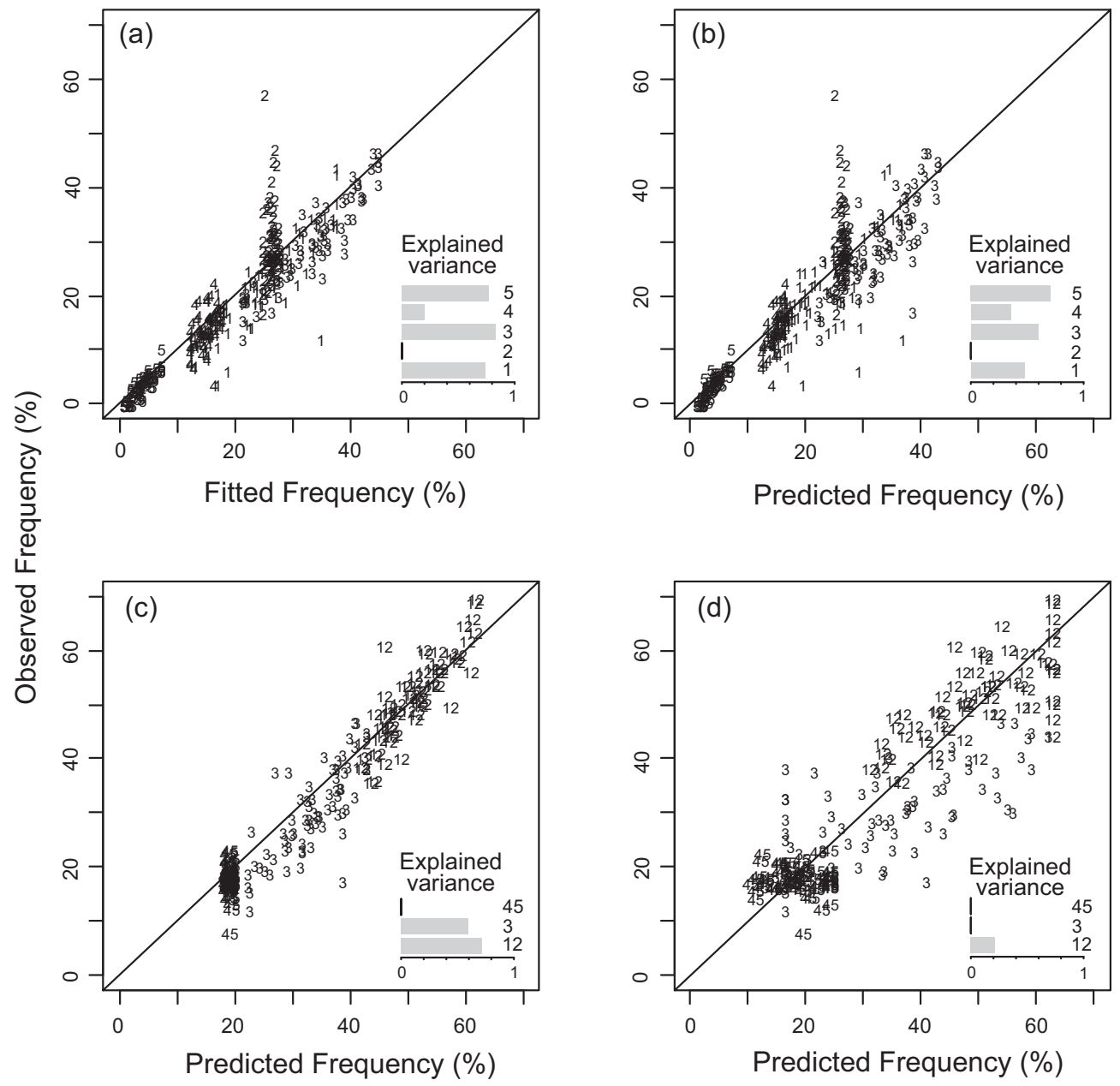

Figure 5. (a) Observed versus fitted frequencies and (b) observed frequencies versus frequencies predicted by our models (equation (3)) for five velocity classes. (c) Observed frequencies versus frequencies predicted by our models (equation (3)) and (d) observed frequencies versus frequencies predicted by a European model (equation (3), Lamouroux et al. [1995, p. 5]) for three classes of velocities common to the two models. The velocity classes are: (1) negative, (2) low $[0 ; 0.5[$, (3) intermediate $[0.5 ; 2[$, (4) high $[2 ; 4.75[$, and $(5)$ very high $(\geq 4.75)$. The symbols " 12 " and " 45 " correspond to groupings of classes 1 and 2 , and 4 and 5 .

models with multivariate habitat suitability models of aquatic species [e.g., Jowett et al., 2008]. However, the low correlation that we observed between point depth and velocities led us to focus on simpler univariate models. In addition, when developing bivariate statistical hydraulic models, Schweizer et al. [2007] found that the average

Table 4. Relationships Between Observed Class Frequencies and Fits or Predictions ${ }^{\mathrm{a}}$

\begin{tabular}{|c|c|c|c|c|c|c|c|c|c|c|c|c|c|c|c|c|}
\hline \multirow[b]{3}{*}{ Variable } & \multirow[b]{3}{*}{ Models } & \multicolumn{15}{|c|}{ Variable Classes } \\
\hline & & \multicolumn{3}{|c|}{$<0$} & \multicolumn{3}{|c|}{$[0-0.5[$} & \multicolumn{3}{|c|}{$[0.5-2[$} & \multicolumn{3}{|c|}{$[2-4.75[$} & \multicolumn{3}{|c|}{$\geq 4.75$} \\
\hline & & $\varepsilon$ & $E V$ & $r^{2}$ & $\varepsilon$ & $E V$ & $r^{2}$ & $\varepsilon$ & $E V$ & $r^{2}$ & $\varepsilon$ & $E V$ & $r^{2}$ & $\varepsilon$ & $E V$ & $r^{2}$ \\
\hline Velocity & equation (1) & 0.03 & 74 & 0.74 & 0.05 & 0 & 0.00 & 0.03 & 83 & 0.84 & 0.02 & 20 & 0.20 & 0.01 & 77 & 0.78 \\
\hline \multirow[t]{2}{*}{5 classes } & equation (3) & 0.05 & 48 & 0.48 & 0.05 & 0 & 0.01 & 0.05 & 60 & 0.60 & 0.02 & 36 & 0.43 & 0.01 & 71 & 0.74 \\
\hline & equation (4) & 0.05 & 33 & 0.34 & 0.05 & 0 & 0.05 & 0.05 & 54 & 0.54 & 0.02 & 40 & 0.56 & 0.01 & 72 & 0.78 \\
\hline \multirow[t]{2}{*}{3 classes } & equation (3) & & & & 0.04 & 72 & 0.74 & 0.05 & 60 & 0.60 & 0.02 & 0 & 0.02 & & & \\
\hline & equation $(2)^{\mathrm{b}}$ & & & & 0.06 & 21 & 0.50 & 0.09 & 0 & 0.42 & 0.04 & 0 & 0.01 & & & \\
\hline Depth & equation (2) & & & & 0.02 & 76 & 0.76 & 0.03 & 76 & 0.76 & 0.02 & 40 & 0.42 & 0.01 & 0 & 0.09 \\
\hline 4 classes & equation (5) & & & & 0.04 & 34 & 0.35 & 0.05 & 38 & 0.40 & 0.02 & 25 & 0.32 & 0.01 & 0 & 0.03 \\
\hline
\end{tabular}

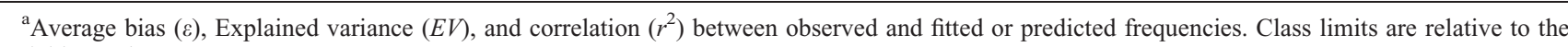
variable reach average.

${ }^{\mathrm{b}}$ From Lamouroux et al. [1995]. 

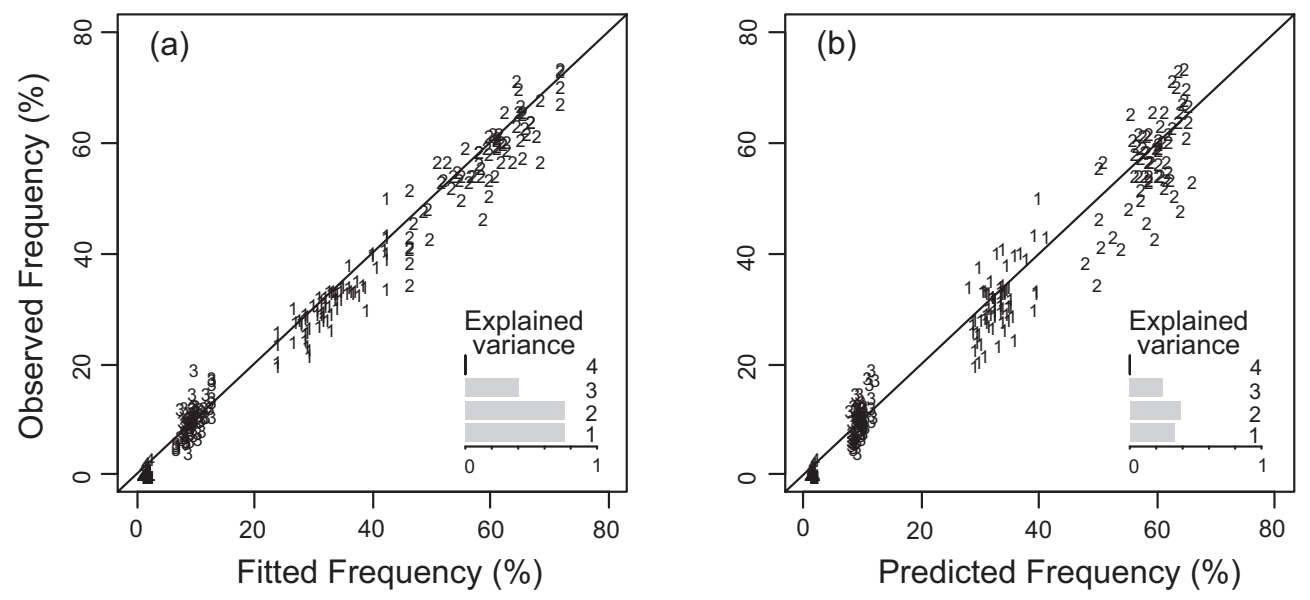

Figure 6. (a) Observed versus fitted frequencies and (b) observed versus frequencies predicted by our models (equation (4)) for four depth classes. The depth classes are: (1) shallow [0; 0.5[, (2) intermediate $[0.5 ; 2[$, (3) deep $[2 ; 4.75[$, and (4) very deep $(\geq 4.75)$.

correlation between depth and velocity was very low (i.e., 0.12 for one of their extreme distributions, 0.01 for the other; see their Table 2). Finally, deriving multivariate hydraulic models may require additional parameters whose link with reach-averaged characteristics is difficult to identify.

[32] Velocity frequencies are much better predicted by our models than by European models. European models adequately predict the average frequency of velocity classes in our steep reaches, suggesting some degree of generality, but they provide only a marginal explanation of the frequency variations of classes across our reaches. By contrast, our model is particularly efficient for predicting negative and intermediate velocities, with $E V$ ranging from 20 to $70 \%$. The mixing parameter of the velocity distributions, $s_{m i x}$, is well-predicted, with a $R^{2}$ equal to 0.74 . This value is comparable to the coefficient of determination $\left(r^{2}\right)$ obtained for the univariate models of European streams [Lamouroux et al., 1995] and the bivariate models of New Zealand [Schweizer et al., 2007] (Table 1). Residuals of the velocity model were not related to the sampling effort (number of verticals, results not shown); poor predictions of $s_{\text {mix }}$ essentially concerned two large streams (Figure 7a) that each had a single large pool. In both these cases, in spite of the care taken to choose a relatively long reach $(>14 \mathrm{~W})$, our sample did not include two consecutive steppool sequences as recommended in Lamouroux et al. [1995], due to the numerous lateral inputs that obliged us to limit reach length. Finally, although the reaches sampled constitute a homogeneous group of streams (steep slope, coarse grain size), the surveys performed in Alpine streams (13 surveys in 5 reaches) were distinguished by velocity (a)

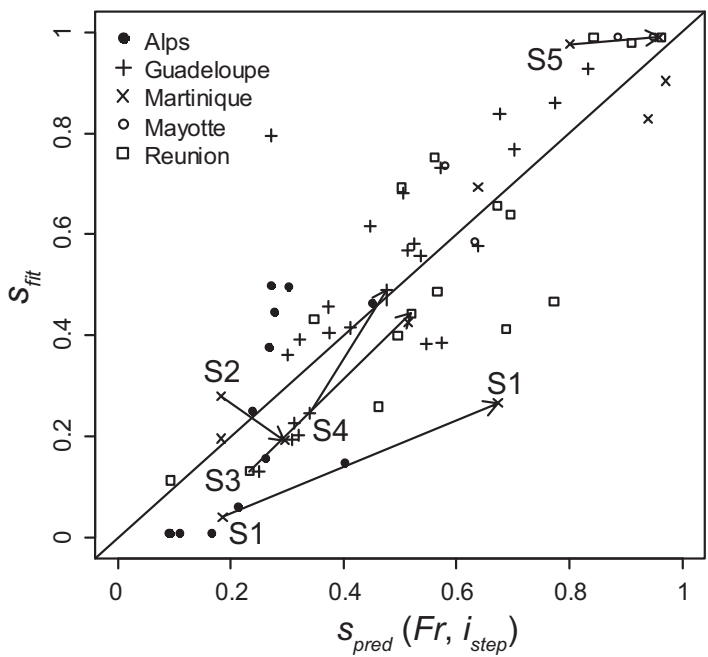

(b)

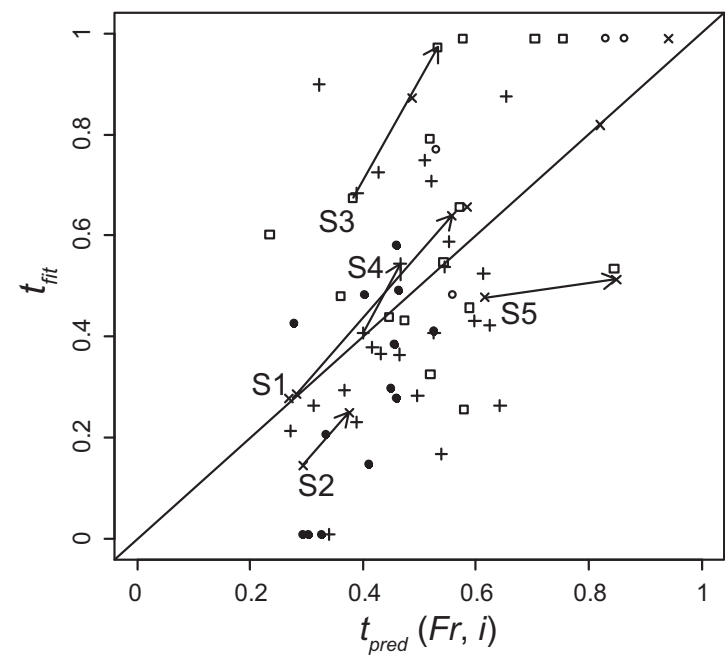

Figure 7. Comparison between (a) $s_{f i t}$ and $s_{\text {pred }}$ (using equation (3)) and (b) $t_{f i t}$ and $t_{\text {pred }}$ (using equation (5)) for 69 surveys from (filled circle) the Alps, (plus) Guadeloupe, (cross) Martinique, (circle) Mayotte, and (square) Reunion. The arrows show variations for a decreasing discharge (ratio of discharges $>4$ ) at five stations S1-S5. 
distributions centered on average values. A refined model specifically adapted to this region could be considered in the future.

[33] Contrary to the results obtained for velocity, the mixing parameter of depth distributions, $t_{m i x}$, was poorly predicted with a $R^{2}$ equal to 0.34 . This can be explained by the strong heterogeneity of bed elevations in our steep streams associated with the presence of large boulders and steps. Difficulties for predicting depth distributions were also encountered for European streams [Lamouroux, 1998], where a model of the variation of $t_{m i x}$ was proposed instead of a model directly predicting $t_{m i x}$. By contrast, $t_{m i x}$ was better predicted in Andean streams of Ecuador [Girard et al., 2013a] where the substrate is less heterogeneous. Nonetheless, depth distributions observed within-reach varied less between streams than velocity distributions, and the bias linked to their prediction was $\leq 5 \%$.

[34] The main reach-scale explanatory variables of the distribution of point hydraulic variables are $F r, i$, and $i_{\text {step }}$. $F r$ is a major predictive variable for the determination of distributions of hydraulic variables in many types of streams. Indeed, Lamouroux et al. [1995] and Girard et al. [2013a] mainly predicted their mixing parameters with Fr. Likewise, Stewardson and McMahon [2002], Schweizer et al. [2007], and Rosenfeld et al. [2011] showed that the mixing parameters of bivariate distributions are mainly determined by $F r$ (Table 1). Fr is the ratio between kinetic and gravitational forces and discriminates torrential and tranquil flows [Yalin, 1992; Wilcox et al., 2011]. In less steep streams, it discriminates the different hydromorphological structures [Jowett, 1993]. When Fr increases within reaches, i.e., generally when discharge increases, velocity and depth distributions both tend to have normal shapes and the mixing parameters $s_{m i x}$ and $t_{m i x}$ decrease. Physically, high $\mathrm{Fr}$ values correspond to high discharge situations where kinetic forces predominate, the influence of form resistance decreases and hydraulic differences between the different geomorphic units decrease [Leopold et al., 1964; Rosenfeld et al., 2011]. Such a longitudinal homogenization usually occurs with a transversal homogenization of the flow [Lamouroux et al., 1995].

[35] The inclusion of $i_{\text {step }}$ in our models shows that spill resistance can affect the distributions of hydraulic variables in our steep streams. This may explain the limited transferability of the European models of Lamouroux et al. [1995] and Lamouroux [1998] to our steep streams, as was observed to a lesser extent in other geographical contexts [Saraeva and Hardy, 2009; Girard et al., 2013a]. Contrary to European observations, neither relative roughness nor coefficients of variation of wetted width are determinants of the distributions of the hydraulic variables in our streams. This suggests that spill resistance is predominant in steep streams, agreeing with Wilcox et al. [2011] who showed that $2 / 3$ of the energy is dissipated in falls in a steep river in the Alps. Nonetheless, the different forms of flow resistance interact in mountain streams [Wilcox et al., 2006; Zimmermann, 2010; David et al., 2011]. Consequently, future research could focus on other parameters responsible for flow resistance in mountain streams. For example, the amplitude of step-pool forms [Wohl and Mer$i t t, 2008]$, the standard error of bed elevation in the longitudinal axis $\left(\sigma_{z}\right)$, bed elevation skew and kurtosis [Coleman et al., 2011], and the relative immersion of the bed $H / \sigma_{z}$ have been identified as determinants of flow resistance [Yochum et al., 2012]. In a large part of our streams with available data we performed tests to determine, unsuccessfully, if the description of average bank slope or other descriptors of particle size distributions improved our models.

[36] We have proposed a simplified velocity distribution model depending only on $F r$, whose performance is quite close to that of our best model. This model may be practical because the explanatory variable $i_{\text {step }}$ is difficult to measure and predict at different discharges. Although measurements of step height along the thalweg at breaks in slope appear sufficient to characterize the longitudinal profile [Zimmermann et al., 2008], the thalweg is sometimes difficult to identify in steep streams where the transversal variability of hydromorphological structures can be high [e.g., Pike et al., 2010; Yochum, 2010].

\section{Conclusions}

[37] Our results demonstrate the potential of statistical models for predicting hydraulic distributions in a wide range of steep streams that generally have step-pool patterns and low width-depth ratios. In such streams, our models improve the predictive power of existing statistical hydraulic models and reveal the significant effect of step height on hydraulic distributions. They predict well the frequency of negative velocities that was not considered by previous models although it can influence sediment and nutrient fluxes. We showed that the Froude number of reaches, already identified as the main predictor of hydraulic distributions in most published statistical models, was also the major predictor of hydraulic distributions in steep streams. This result suggests that developing general statistical models from all available data sets could be possible. However, it should be kept in mind that most statistical models have been developed for streams with limited morphologic alterations and under low to intermediate flow rates.

[38] The simplicity and generality of statistical habitat models is attractive for habitat simulation applications such as the determination of ecological flows at the scale of stream reaches or whole catchments [Snelder et al., 2011]. For such applications, hydraulic models are linked to preference models of aquatic taxa [Girard et al., 2013b] and the knowledge of hydraulic distributions is needed over a range of discharges. This information is generally difficult to obtain by repeated field measurements at many discharges, whereas the input of statistical hydraulic models (i.e., the at-a-reach hydraulic geometry relationships) can be extrapolated from measurements at a few discharge rates or estimated from regional models [Stewardson, 2005; Snelder et al., 2011]. The transferability across streams of statistical hydraulic models and preference models for aquatic taxa [Lamouroux et al., 2013] is an important requirement of catchment applications, e.g., for improving water allocation rules based on habitat values [Snelder et al., 2011]. Furthermore, the development of geostatistical hydraulic models [Legleiter et al., 2007; Trevisani et al., 2010] is also an attractive perspective to describe 
hydraulic spatial patterns used by aquatic species [Monti and Legendre, 2009].

\section{Appendix A}

[39] Our models predict the frequency distributions of velocity $\left(f_{u}\right)$ and depth $\left(f_{h}\right)$ as a mixture of two extreme empirical distributions (Table A1): one with large variance $\left(f_{u}^{1}\right.$ for velocity or $f_{h}^{1}$ for depth) and one with small variance $\left(f_{u}^{2}\right.$ or $\left.f_{h}^{2}\right)$.

Table A1. Empirical Extreme Distributions of Velocity and Depth Combined in the Statistical Models

\begin{tabular}{|c|c|c|c|c|c|}
\hline \multicolumn{2}{|c|}{ Class Limits } & \multicolumn{2}{|c|}{$u / U$} & \multicolumn{2}{|c|}{$h / H$} \\
\hline Minimum & Maximum & $f_{u}^{1}$ & $f_{u}^{2}$ & $f_{h}^{1}$ & $f_{h}^{2}$ \\
\hline$-\operatorname{Inf}$ & -0.001 & 0.3677 & 0.1133 & & \\
\hline-0.001 & 0.250 & 0.1718 & 0.1671 & 0.2215 & 0.1079 \\
\hline 0.250 & 0.500 & 0.0709 & 0.1046 & 0.1938 & 0.1207 \\
\hline 0.500 & 0.750 & 0.0500 & 0.0917 & 0.1174 & 0.1487 \\
\hline 0.750 & 1.000 & 0.0430 & 0.0763 & 0.1100 & 0.1387 \\
\hline 1.000 & 1.250 & 0.0374 & 0.0762 & 0.0741 & 0.1672 \\
\hline 1.250 & 1.500 & 0.0322 & 0.0750 & 0.0714 & 0.1145 \\
\hline 1.500 & 1.750 & 0.0253 & 0.0665 & 0.0549 & 0.0892 \\
\hline 1.750 & 2.000 & 0.0198 & 0.0578 & 0.0260 & 0.0560 \\
\hline 2.000 & 2.250 & 0.0190 & 0.0584 & 0.0245 & 0.0244 \\
\hline 2.250 & 2.500 & 0.0115 & 0.0369 & 0.0212 & 0.0221 \\
\hline 2.500 & 2.750 & 0.0187 & 0.0252 & 0.0158 & 0.0105 \\
\hline 2.750 & 3.000 & 0.0163 & 0.0241 & 0.0183 & 0.0000 \\
\hline 3.000 & 3.250 & 0.0128 & 0.0141 & 0.0104 & 0.0000 \\
\hline 3.250 & 3.500 & 0.0122 & 0.0033 & 0.0069 & 0.0000 \\
\hline 3.500 & 3.750 & 0.0067 & 0.0069 & 0.0056 & 0.0000 \\
\hline 3.750 & 4.000 & 0.0077 & 0.0026 & 0.0034 & 0.0000 \\
\hline 4.000 & 4.250 & 0.0033 & 0.0000 & 0.0014 & 0.0000 \\
\hline 4.250 & 4.500 & 0.0061 & 0.0000 & 0.0034 & 0.0000 \\
\hline 4.500 & 4.750 & 0.0017 & 0.0000 & 0.0061 & 0.0000 \\
\hline 4.750 & $+\operatorname{Inf}$ & 0.0657 & 0.0000 & 0.0140 & 0.0000 \\
\hline
\end{tabular}

[40] Acknowledgments. We acknowledge the help from many colleagues for field collections and advice, in particular from AsconitConsultants, Irstea Lyon, Université de Lyon 1, DREAL Guadeloupe, Parc National de la Guadeloupe, DEAL Mayotte, BRGM Mayotte, Université des Antilles et de la Guyane, OIE Martinique, OIE Réunion, and ARDA Réunion. We thank Steven Yochum, two anonymous reviewers, the editors and Catherine Leigh for their comments on earlier drafts.

\section{References}

Bathurst, J. C. (2002), At-a-site variation and minimum flow resistance for mountain rivers, J. Hydrol., 269(1-2), 11-26.

Blott, S. J., and K. Pye (2001), GRADISTAT: A grain size distribution and statistics package for the analysis of unconsolidated sediments, Earth Surf. Processes Landforms, 26(11), 1237-1248.

Chaperon, P., Y. L'Hote, and G. Vuillaume (1983), Les ressources en eau de surface de la Guadeloupe, Cah. ORSTOM, Sér. Hydrol., 20(3-4), 149-178.

Chiu, C. L., and N. C. Tung (2002), Maximum velocity and regularities in open-channel flow, J. Hydraul. Eng., 128(4), 390-398.

Coleman, S. E., V. I. Nikora, and J. Aberle (2011), Interpretation of alluvial beds through bed-elevation distribution moments, Water Resour. Res., 47, W11505, doi:10.1029/2011WR010672.

Conallin, J., E. Boegh, and J. K. Jensen (2010), Instream physical habitat modelling types: An analysis as stream hydromorphological modelling tools for EU water resource managers, Int. J. River Basin Manage., 8(1), 93-107.

Cooper, J. R., and S. J. Tait (2010), Spatially representative velocity measurement over water-worked gravel beds, Water Resour. Res., 46, W11559, doi:10.1029/2009WR008465.
David, G. C. L., E. Wohl, S. E. Yochum, and B. P. Bledsoe (2010), Controls on at-a-station hydraulic geometry in steep headwater streams, Colorado, USA, Earth Surf. Processes Landforms, 35(15), 1820-1837.

David, G. C. L., E. Wohl, S. E. Yochum, and B. P. Bledsoe (2011), Comparative analysis of bed resistance partitioning in high-gradient streams, Water Resour. Res., 47, W07507, doi:10.1029/2010WR009540.

Dingman, S. L. (1989), Probability distribution of velocity in natural channel cross sections, Water Resour. Res., 25(3), 509-518.

Einstein, H. A., and N. L. Barbarossa (1952), River channel roughness, Trans. Am. Soc. Civ. Eng., 117, 1121-1146.

Ferguson, R. (2007), Flow resistance equations for gravel- and boulderbed streams, Water Resour. Res., 43, W05427, doi:10.1029/2006WR 005422 .

Girard, V., P. Le Goulven, R. Calvez, and N. Lamouroux (2013a), Velocity and depth distributions in stream reaches: Testing European models in Ecuador, J. Hydraul. Eng., 139, 794-798.

Girard, V., D. Monti, P. Valade, N. Lamouroux, J. P. Mallet, and H. Grondin (2013b), Hydraulic preferences of shrimps and fishes in tropical insular rivers, River Res. Appl., doi:10.1002/rra.2675.

Jowett, I. G. (1993), A method for objectively identifying pool, run, and riffle habitats from physical measurements, N. Z. J. Mar. Freshwater Res., 27(2), 241-248.

Jowett, I. G., S. M. Parkyn, and J. Richardson (2008), Habitat characteristics of crayfish (Paranephrops planifrons) in New Zealand streams using generalised additive models (GAMs), Hydrobiologia, 596, 353-365.

Lamouroux, N. (1998), Depth probability distributions in stream reaches, J. Hydraul. Eng., 124(2), 224-227.

Lamouroux, N. (2007), Hydraulic geometry of stream reaches and ecological implications, in Developments in Earth Surface Processes Gravel Bed Rivers VI, edited by H. Habersack, H. Piégay, and M. Rinaldi, pp. 661-675, Elsevier, Amsterdam, Netherlands.

Lamouroux, N., B. Statzner, U. Fuchs, F. Kohmann, and U. Schmedtje (1992), An unconventional approach to modeling spatial and temporal variability of local shear-stress in stream segments, Water Resour. Res., 28(12), 3251-3258.

Lamouroux, N., Y. Souchon, and E. Herouin (1995), Predicting velocity frequency-distributions in stream reaches, Water Resour. Res., 31(9), 2367-2375.

Lamouroux, N., S. Mérigoux, S. Dolédec, and T. H. Snelder (2013), Transferability of hydraulic preference models of aquatic macroinvertebrates, River Res. Appl., 29, 933-937.

Lee, A. J., and R. I. Ferguson (2002), Velocity and flow resistance in steppool streams, Geomorphology, 46(1-2), 59-71.

Legleiter, C. J., T. L. Phelps, and E. E. Wohl (2007), Geostatistical analysis of the effects of stage and roughness on reach-scale spatial patterns of velocity and turbulence intensity, Geomorphology, 83(3-4), $322-345$.

Legleiter, C. J., P. C. Kyriakidis, R. R. McDonald, and J. M. Nelson (2011), Effects of uncertain topographic input data on two-dimensional flow modelling in a gravel-bed river, Water Resour. Res., 47, W03518, doi: 10.1029/2010WR009618.

Leopold, L. B., M. G. Wolman, and J. P. Miller (1964), Fluvial Processes in Geomorphology, pp. 522, W. H. Freeman, San Francisco, Calif.

Malavoi, J. R., and Y. Souchon (2002), Standardized description of streams and rivers channel geomorphic units: Qualitative description key and physical measurements, Knowl. Manage. Aquat. Ecosyst., 365/366, 357-372.

Marchand, J. P., R. D. Jarrett, and L. L. Jones (1984), Velocity profile, water-surface slope and bed-material size for selected streams in Colorado, U. S. Geol. Surv. Open File Rep., 84-733.

McFadden, D. (1974), Conditional logit analysis of qualitative choice behavior, in Frontiers in Econometrics, edited by P. Zarembka, pp. 105142, Academic Press, New York, N. Y.

Montgomery, D. R., and J. M. Buffington (1997), Channel-reach morphology in mountain drainage basins, Bull. Geol. Soc. Am., 109(5), 596-611.

Monti, D., and P. Legendre (2009), Shifts between biotic and physical driving forces of species organization under natural disturbance regimes, Can. J. Fish. Aquat. Sci., 66, 1282-1293.

Nikora, V. I. (2009), Hydrodynamics of aquatic ecosystems: An interface between ecology, biomechanics and environmental fluid mechanics, River Res. Appl., 26(4), 367-384.

Petts, G. E. (2009), Instream flow science for sustainable river management, J. Am. Water Resour. Assoc., 45(5), 1071-1086. 
Pike, A. S., F. N. Scatena, and E. E. Wohl (2010), Lithological and fluvial controls on the geomorphology of tropical montane stream channels in Puerto Rico, Earth Surf. Processes Landforms, 35(12), 1402-1417.

Poff, N. L., and J. D. Allan (1995), Functional organization of stream fish assemblages in relation to hydrological variability, Ecology, 76(2), 606627.

R Development Core Team (2010), R: A Language and Environment for Statistical Computing, R Found. for Stat. Comput., Vienna. [Available at http://www.R-project.org/.].

Rickenmann, D., and A. Recking (2011), Evaluation of flow resistance in gravel-bed rivers through a large field data set, Water Resour. Res., 47, W07538, doi:10.1029/2010WR009793.

Robert, R. (2001), Pluviométrie à l'île de la Réunion: Des travaux de J. de Defos (1960) à nos jours, L'Inform. Géogr., 65(1), 53-59.

Rosenfeld, J. S., K. Campbell, E. S. Leung, J. Bernhardt, and J. Post (2011), Habitat effects on depth and velocity frequency distributions: Implications for modeling hydraulic variation and fish habitat suitability in streams, Geomorphology, 130(3-4), 127-135.

Saraeva, K., and T. B. Hardy (2009), Prediction of fisheries physical habitat values based on hydraulic geometry and frequency distributions of depth and velocity, Inter. J. River Basin Manage., 7(1), 31-41.

Schweizer, S., M. E. Borsuk, I. Jowett, and P. Reichert (2007), Predicting joint frequency distributions of depth and velocity for instream habitat assessment, River Res. Appl., 23(3), 287-302.

Smith, M. W., N. J. Cox, and L. J. Bracken (2011), Modeling depth distributions of overland flows, Geomorphology, 125(3), 402-413.

Snelder, T., D. Booker, and N. Lamouroux (2011), A method to assess and define environmental flow rules for large jurisdictional regions, $\mathrm{J}$. Am. Water Resour. Assoc., 47(4), 828-840.

Stewardson, M. J. (2005), Hydraulic geometry of stream reaches, $J$. Hydrol., 306(1-4), 97-111.
Stewardson, M. J., and T. A. McMahon (2002), A stochastic model of hydraulic variations within stream channels, Water Resour. Res., 38(1), 1845, doi: 10.1029/2000WR000014.

Trevisani, S., M. Cavalli, and L. Marchi (2010), Reading the bed morphology of a mountain stream: A geomorphometric study on high-resolution topographic data, Hydrol. Earth Syst. Sci., 14(2), 393-405.

Wiberg, P. L., and J. D. Smith (1991), Velocity distribution and bed roughness in high gradient streams, Water Resour. Res., 27(5), 825-838.

Wilcox, A. C., J. M. Nelson, and E. E. Wohl (2006), Flow resistance dynamics in step-pool channels: 2. Partitioning between grain, spill, and woody debris resistance, Water Resour. Res., 42, W05419, doi:10.1029/ 2005 WR004278.

Wilcox, A. C., E. E. Wohl, F. Comiti, and L. Mao (2011), Hydraulics, morphology, and energy dissipation in an alpine step-pool channel, Water Resour. Res., 47, W07514, doi:10.1029/2010WR010192.

Wohl, E., and D. M. Thompson (2000), Velocity characteristics along a small steep-pool channel, Earth Surf. Processes Landforms, 25, 353367.

Wohl, E., and D. M. Merritt (2008), Reach-scale channel geometry of mountain streams, Geomorphology, 93(3-4), 168-185.

Yalin, M.S. (1992), River Mechanics, Pergamon, New York.

Yochum, S. E. (2010), Flow resistance prediction in high-gradient streams, $\mathrm{PhD}$ dissertation, Colo. State Univ., Fort Collins, Colo.

Yochum, S. E., B. P. Bledsoe, G. C. L. David, and E. Wohl (2012), Velocity prediction in high-gradient channels, J. Hydrol., 424, 84-98.

Zimmermann, A. (2010), Flow resistance in steep streams: An experimental study, Water Resour. Res., 46, W09536, doi:10.1029/2009WR 007913.

Zimmermann, A. E., M. Church, and M. A. Hassan (2008), Identification of steps and pools from stream longitudinal profile data, Geomorphology, 102(3-4), 395-406. 